Article

\title{
Ag-Modified $\mathrm{In}_{2} \mathrm{O}_{3}$ Nanoparticles for Highly Sensitive and Selective Ethanol Alarming
}

\author{
Jinxiao Wang ${ }^{1,2}$, Zheng Xie ${ }^{1}$, Yuan $\mathrm{Si}^{3}$, Xinyi Liu ${ }^{3}$, Xinyuan Zhou ${ }^{1}$, Jianfeng Yang ${ }^{4}$, Peng Hu ${ }^{1}$, \\ Ning Han ${ }^{1, *}$ (1), Jun Yang ${ }^{2, *}$ and Yunfa Chen ${ }^{1}$ \\ 1 State Key Laboratory of Multiphase Complex Systems, Institute of Process Engineering, Chinese Academy \\ of Sciences, Beijing 100190, China; wangjinxiao@stu.xjtu.edu.cn (J.W.); zheng163xie@163.com (Z.X.); \\ zhouxinyuan14@mails.ucas.ac.cn (X.Z.); pengh@bjut.edu.cn (P.H.); chenyf@ipe.ac.cn (Y.C.) \\ 2 School of Metallurgical Engineering, Xi'an University of Architecture and Technology, Xi'an 710055, China \\ 3 Beijing ChenJingLun High School, Beijing 100101, China; siyuan0517@126.com (Y.S.); siww@x263.net (X.L.) \\ 4 State Key Laboratory for Mechanical Behavior of Materials, Xi'an Jiaotong University, Xi'an 710049, China; \\ yang155@mail.xjtu.edu.cn \\ * Correspondence: nhan@ipe.ac.cn (N.H.); yj-yangjun@xauat.edu.cn (J.Y.); Tel.: +86-10-6255-8356 (N.H.); \\ +86-131-5242-0820 (J.Y.)
}

Received: 31 August 2017; Accepted: 26 September 2017; Published: 27 September 2017

\begin{abstract}
Pure $\operatorname{In}_{2} \mathrm{O}_{3}$ nanoparticles are prepared by a facile precipitation method and are further modified by Ag. The synthesized samples are characterized by scanning electron microscopy, transmission electron microscopy, energy dispersive $\mathrm{X}$-ray spectroscopy, $\mathrm{X}$-ray diffraction, Raman and UV-Vis spectra. The results show the successful heterojunction formation between $\mathrm{Ag}$ and $\operatorname{In}_{2} \mathrm{O}_{3}$. Gas sensing property measurements show that the $5 \mathrm{~mol} \%$ Ag-modified $\mathrm{In}_{2} \mathrm{O}_{3}$ sensor has the response of 67 to $50 \mathrm{ppm}$ ethanol, and fast response and recovery time of 22.3 and $11.7 \mathrm{~s}$. The response is over one magnitude higher than that of pure $\operatorname{In}_{2} \mathrm{O}_{3}$, which can be attributed to the enhanced catalytic activity of Ag-modified $\mathrm{In}_{2} \mathrm{O}_{3}$ as compared with the pure one. The mechanism of the gas sensor can be explained by the spillover effect of $\mathrm{Ag}$, which enhances the oxygen adsorption onto the surface of $\mathrm{In}_{2} \mathrm{O}_{3}$ and thus give rise to the higher activity and larger surface barrier height.
\end{abstract}

Keywords: $\mathrm{In}_{2} \mathrm{O}_{3}$ nanoparticles; Ag modification; heterojunction; high response; ethanol sensing

\section{Introduction}

Each year, a large number of traffic accidents are triggered by drunk driving, causing serious casualties and property losses. Therefore, strict regulations have been made by traffic management organizations to limit drunk driving, and many kinds of methods such as electrochemical sensors have been used for the rapid detection of alcohol concentration in exhaled breath. Due to their low-cost and simple operation, semiconductor metal oxide (SMOX) gas sensors have gained wide attention [1-7]. $\mathrm{In}_{2} \mathrm{O}_{3}$ is a typical n-type semiconductor with a wide band gap of about $2.8 \mathrm{eV}$, and has been used in gas sensors due to its high specific surface areas [8-11]. However, pure $\operatorname{In}_{2} \mathrm{O}_{3}$ gas sensors have inadequate sensitivity to low concentrations of ethanol for making better judgments about whether the subject is inebriated. For example, according to the Chinese standard (GB 19522-2010), there are two types of penalties for drunk driving: drunk driving (breath alcohol concentration exceeds $177 \mathrm{ppm}$ ) and driving after drinking (breath alcohol concentration is 44 177 ppm). Similar constraints have been recommended by World Health Organization and many other countries in the world. Consequently, the sensitivity of $\mathrm{In}_{2} \mathrm{O}_{3}$ should be improved to a detection limit of $<44 \mathrm{ppm}$ ethanol in order to screen drinkers quickly.

Commonly, the sensing properties of $\operatorname{In}_{2} \mathrm{O}_{3}$ are tailored by morphology control, structure modification, and decoration with metal oxides to for heterojunction [12-16], as well as modified with 
noble metals $[17,18]$ in the matrix surface area. For example, hierarchical $\operatorname{In}_{2} \mathrm{O}_{3}$ microbundles and flowers were prepared, showing a response of 11-14 to $50 \mathrm{ppm}$ ethanol [12,15]. Anand [18] utilized Tb to dope $\mathrm{In}_{2} \mathrm{O}_{3}$ nanorods, which showed a high response of 40 to $50 \mathrm{ppm}$ ethanol. Meanwhile, noble metals are commonly used as surface modifiers to enhance the response of MOX sensors. For instance, $\mathrm{Pd}$ can enhance the sensitivity of $\operatorname{In}_{2} \mathrm{O}_{3}$ to ethanol with a response of 50 to $100 \mathrm{ppm}$ [19]. However, $\mathrm{Au}$ nanoparticle decoration on $\mathrm{In}_{2} \mathrm{O}_{3}$ can only obtain the response of 6.5 to $100 \mathrm{ppm}$ ethanol [17]. Therefore, the performance enhancement of $\operatorname{In}_{2} \mathrm{O}_{3}$ gas sensors should be further improved to obtain a high response to ethanol. In the meantime, the resistance of the gas sensors should be in the $\mathrm{k} \Omega$ level in order to be easily integrated with electronic circuits. In contrast, complicated circuit design should be adopted and a higher cost is thus unavoidable. Therefore, there exist trade-offs between the parameters of a gas sensor, including sensitivity, response/recovery time, resistance level, etc.

In this study, pure $\mathrm{In}_{2} \mathrm{O}_{3}$ were prepared by a simple precipitation method, and were then modified by Ag to form a surface heterojunction. The gas sensing properties of pure $\operatorname{In}_{2} \mathrm{O}_{3}$ and Ag-modified $\mathrm{In}_{2} \mathrm{O}_{3}$ were compared and the catalytic performances were evaluated. The results show that Ag can greatly improve the ethanol sensing property of $\mathrm{In}_{2} \mathrm{O}_{3}$, demonstrating a response of 67 to $50 \mathrm{ppm}$ at a sensor resistance of about $10 \mathrm{kOhm}$. The mechanism is attributable to the enhanced ethanol catalytic property of $\mathrm{In}_{2} \mathrm{O}_{3}$ by Ag with a significant spillover effect.

\section{Materials and Methods}

\subsection{Synthesis of $\mathrm{Ag}$-Modified $\mathrm{In}_{2} \mathrm{O}_{3}$ Nanoparticles}

The $0.5 \mathrm{~mol} \cdot \mathrm{L}^{-1} \mathrm{NH}_{3} \cdot \mathrm{H}_{2} \mathrm{O}$ solution was added dropwise into $10 \mathrm{~mL} 1 \mathrm{~mol} \cdot \mathrm{L}^{-1} \mathrm{InCl}_{3}$ aqueous solution at $60{ }^{\circ} \mathrm{C}$. After the $\mathrm{pH}$ was adjusted to 8.5 , the solution was then heated for about $30 \mathrm{~min}$ and then cooled down to room temperature. Subsequently, the precipitate was rinsed, dried, and calcined at $600{ }^{\circ} \mathrm{C}$ for $2 \mathrm{~h}$ to obtain the pure $\operatorname{In}_{2} \mathrm{O}_{3}$ product.

In $\mathrm{Ag}$ modification, the $\mathrm{In}_{2} \mathrm{O}_{3}$ was mixed uniformly with $0.03 \mathrm{~mol} \cdot \mathrm{L}^{-1} \mathrm{AgNO}_{3}$ solution. The molar ratio $(\mathrm{Ag} / \mathrm{In})$ was $1,5,10$, and $20 \mathrm{~mol} \%$, respectively. After water was completely evaporated at $100{ }^{\circ} \mathrm{C}$, the mixture was calcined at $500{ }^{\circ} \mathrm{C}$ for $2 \mathrm{~h}$ in a tube furnace and then cooled down to room temperature. Eventually, the product was obtained after it was ground with an agate mortar.

\subsection{Characterization}

The crystalline phase determination was carried out by X-ray powder diffraction (XRD, Panalytical X'pert Pro, Alemlo, The Netherlands, $\mathrm{Cu}-\mathrm{K} \alpha$ radiation of $\lambda=0.15406 \mathrm{~nm}, 40 \mathrm{kV}$, $40 \mathrm{~mA}$ ). The morphologies and energy dispersive X-ray spectra (EDS) were characterized by a field-emission scanning electron microscope (FE-SEM, JEOL JSM-6700F, Tokyo, Japan 5 kV, $10 \mu \mathrm{A}$ ). The microstructures were investigated by high-resolution transmission electron microscopy (HRTEM, JEOL JEM-2010F, Tokyo, Japan, 200 kV, $100 \mu \mathrm{A}$ ). The optical properties were test by Raman (532 $\mathrm{nm}$ argon laser, Invia-Reflex $20 \mathrm{~mW}$, Renishaw, London, Britain) and UV-Vis spectra (300UV-vis spectrophotometer, Thermo Scientific, Waltham, MA, USA). The catalytic evaluation of ethanol was analyzed by using a gas chromatograph (Shimadzu GC-2014, Tokyo, Japan).

The gas sensing performance of the sensors was measured by using a WS-30A Gas sensor test system (Zhengzhou Winsen Electronics Technology Co. Ltd., Zhengzhou, China) according to previous studies [20-22]. The samples were ultrasonically dispersed with a suitable amount of ethanol. Then, the mixture was extracted with a micro-syringe and dribbled onto the surface of a substrate with a pair of Au electrodes on both ends. A Ni-Cr heating wire went through the substrate to serve as a heating filament, and the operating temperature was controlled by tuning the heating voltage. The gas response is defined as the ratio of $R_{a} / R_{g}$, where $R_{a}$ and $R_{g}$ are the resistances of the sensor in the air and tested gas, respectively. 


\section{Results}

\subsection{Synthesis and Characterization}

The SEM images of $\mathrm{In}_{2} \mathrm{O}_{3}$-based nanomaterials (Figure 1) demonstrate that the pure $\operatorname{In}_{2} \mathrm{O}_{3}$ and 5 mol \% Ag-modified $\mathrm{In}_{2} \mathrm{O}_{3}$ have similar morphologies of nanoparticles with diameters of about 50 $\mathrm{nm}$. It is difficult to distinguish Ag nanoparticles from the image due to the inadequate magnification. Then EDS elemental analysis was carried out with the mapping and spectra of $5 \mathrm{~mol} \%$ Ag-modified $\mathrm{In}_{2} \mathrm{O}_{3}$ nanomaterials, as shown in Figure 2. It can be seen clearly that the Ag element is identified in the EDS mapping and the spectrum. We can calculate the Ag concentration to be $4.4 \mathrm{~mol} \%$, which is similar to the Ag concentration (5 mol \%) in the experimental design.
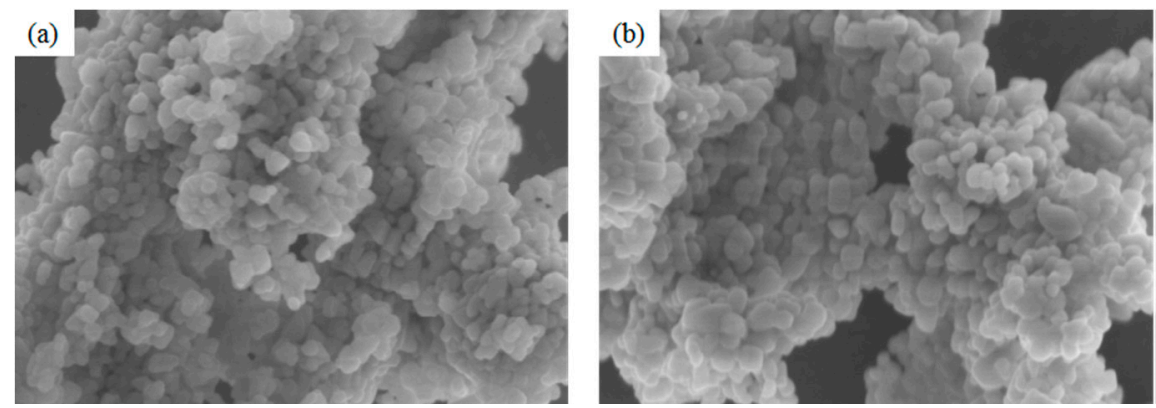

Figure 1. SEM images of (a) pure and (b) $5 \mathrm{~mol} \%$ Ag-modified $\mathrm{In}_{2} \mathrm{O}_{3}$ nanomaterials.
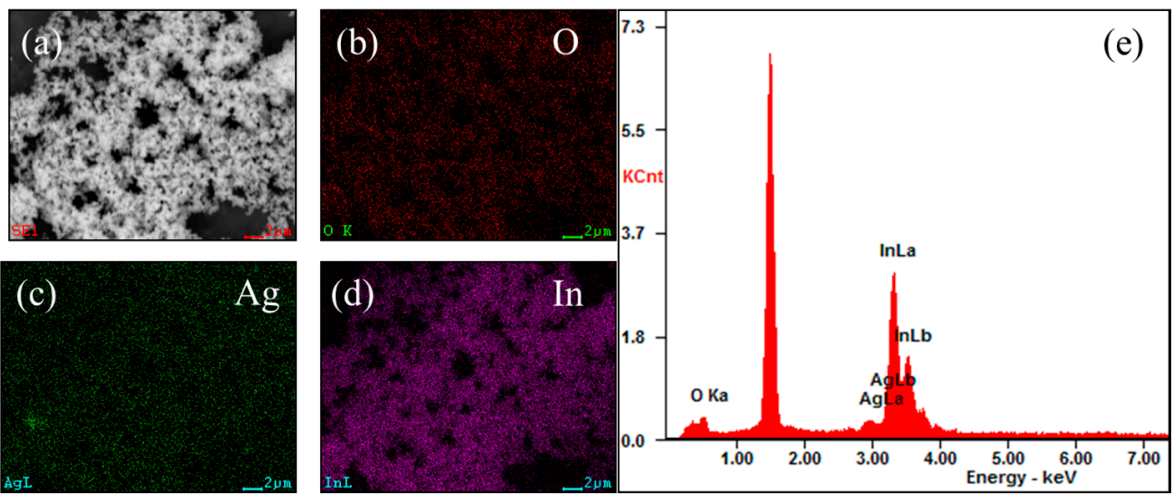

Figure 2. SEM images, element mapping and EDS spectrum of $5 \mathrm{~mol} \%$ Ag-modified $\operatorname{In}_{2} \mathrm{O}_{3}$ nanomaterials. (a) SEM image; (b) O; (c) Ag; (d) In mapping; and (e) EDS spectrum.

$\mathrm{X}$-ray diffraction $(\mathrm{XRD})$ is then used to determine the crystal structure of the products as shown in Figure 3a. It is clear that the peaks of pure $\mathrm{In}_{2} \mathrm{O}_{3}$ are (211), (222), (400), (440), (620), which can be indexed to the cubic structure of $\operatorname{In}_{2} \mathrm{O}_{3}$ (PDF No. 01-071-2194). This shows that the pure $\operatorname{In}_{2} \mathrm{O}_{3}$ has good crystallinity. The diffraction peak of $\mathrm{Ag}$ (111) can be found clearly at $5 \mathrm{~mol} \% \mathrm{Ag}$-modified $\mathrm{In}_{2} \mathrm{O}_{3}[10,23,24]$. To further identify the Ag nanoparticles, HRTEM images were obtained, as shown in Figure 3b. It is clearly seen that the $\mathrm{In}_{2} \mathrm{O}_{3}$ particles are approximately $50 \mathrm{~nm}$ and the smaller $\mathrm{Ag}$ nanoparticles (about $10 \mathrm{~nm}$ ) are pinned on the $\mathrm{In}_{2} \mathrm{O}_{3}$ surface (Figure $3 \mathrm{~b}$ ). Furthermore, the lattice spacing of $0.215 \mathrm{~nm}$ corresponds to the $\mathrm{In}_{2} \mathrm{O}_{3}$ (332) plane, and the lattice spacing of $0.204 \mathrm{~nm}$ corresponds to the $\mathrm{Ag}(200)$ plane. These results indicate that the $\mathrm{In}_{2} \mathrm{O}_{3}$ has been successfully modified by $\mathrm{Ag}$, forming a heterostructure.

The structural and optical properties are then characterized by Raman and UV-Vis spectra as shown in Figure 4. The peaks at around 305, 366, 495, and $630 \mathrm{~cm}^{-1}$ in Figure 4a fit well with the bcc-structured indium oxide [25]. Also, the peak around $305 \mathrm{~cm}^{-1}$ belongs to the bending vibration of $\mathrm{InO}_{6}$, the peak around $366 \mathrm{~cm}^{-1}$ belongs to the stretching vibration of In-O-In, and those around 495 
and $630 \mathrm{~cm}^{-1}$ are attributed to the stretching vibration of $\operatorname{lnO}_{6}$. We found that the Raman peaks nearly disappeared with Ag addition. The Ag may lead to a strong fluorescence and thus the stretching vibration and bending vibration are greatly reduced [26]. The UV-Vis absorption spectra of the pure and Ag-modified $\mathrm{In}_{2} \mathrm{O}_{3}$ are clarified in Figure $4 \mathrm{~b}$. The pure $\mathrm{In}_{2} \mathrm{O}_{3}$ exhibits light absorption at about $<480 \mathrm{~nm}$, from which we can calculate the band gap of pure $\mathrm{In}_{2} \mathrm{O}_{3}$ to be about $2.8 \mathrm{eV}$ according to the Kubelka-Munk equation [24]. This result is basically the same as that in previous studies [8,11]. However, the absorption edge is greatly extended to the visible light region of about $700 \mathrm{~nm}$, which is probably due to the surface plasmon response absorption of Ag nanoparticles as reported in the literature [24]. The Ag plasmonic absorption is dependent on the diameter of the nanoparticles (red shift with increased diameter) [27]; therefore, the absorption in the 400-700 $\mathrm{nm}$ range in this study showed the large Ag size distribution [25].
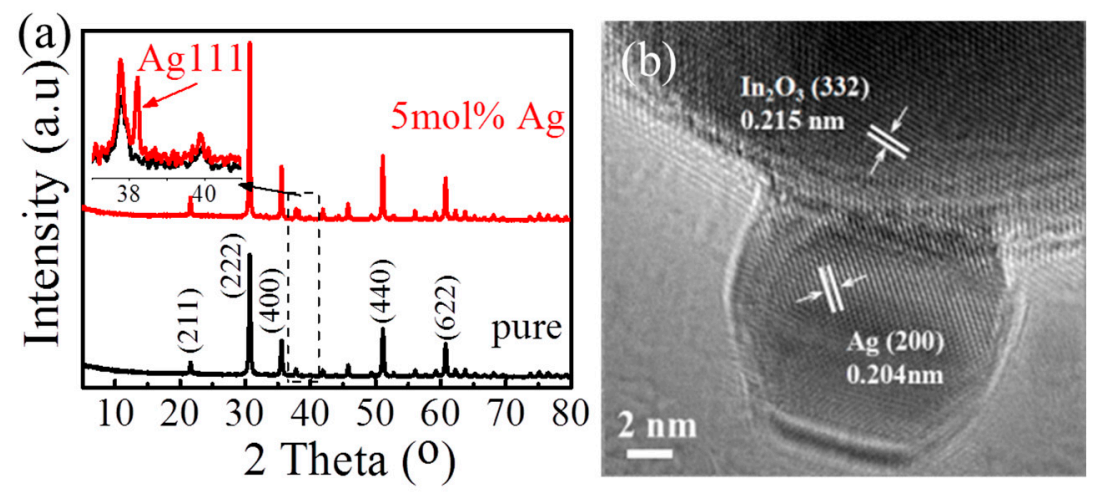

Figure 3. (a) XRD patterns of pure and $5 \mathrm{~mol} \%$ Ag-modified $\operatorname{In}_{2} \mathrm{O}_{3}$ nanomaterials, and (b) HRTEM images of $5 \mathrm{~mol} \%$ Ag-modified $\mathrm{In}_{2} \mathrm{O}_{3}$ nanomaterials.
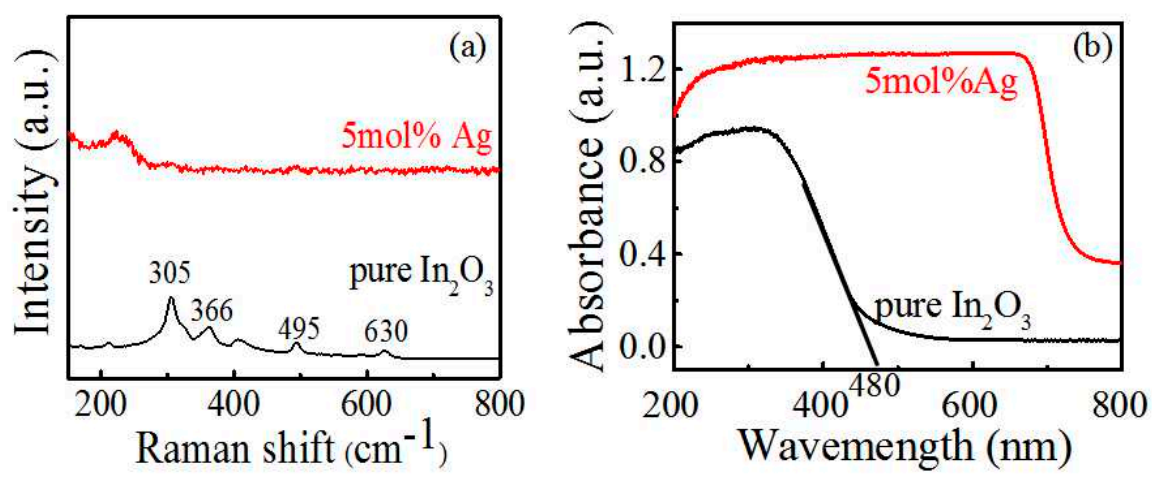

Figure 4. (a) Raman spectra and (b) UV-Vis spectra of pure and $5 \mathrm{~mol} \%$ Ag-modified $\mathrm{In}_{2} \mathrm{O}_{3}$ nanomaterials.

\subsection{The Gas Sensing Properties}

The gas sensing properties of pure and Ag-modified $\mathrm{In}_{2} \mathrm{O}_{3}$ are measured by static method. The optimum operating condition is firstly investigated for ethanol detection, as shown in Figure 5 . Commonly, at low temperatures, less active sites at the semiconductor surface lead to the insufficient reaction of the target gas. The target gas interacts more easily with the sensors at increased work temperatures, resulting in the response improvement. Nonetheless, upon further increasing the working temperature, the charge-carrier concentration and the conductivity increase and the Debye length decreases [14], which leads to the decrease of the response. Figure 5 demonstrates the response of pure and Ag-modified $\operatorname{In}_{2} \mathrm{O}_{3}$ under the different operating temperatures for $50 \mathrm{ppm}$ ethanol. The response values increase first and then decrease with the rise of the operating temperature, and 
reach the maximum at $300{ }^{\circ} \mathrm{C}$ for all samples. We also tried to tailor the $\mathrm{In}_{2} \mathrm{O}_{3}$ nanoparticle size by precipitating $\operatorname{In}(\mathrm{OH})_{3}$ at varied temperatures of 40 and $80{ }^{\circ} \mathrm{C}$ in order to tune the gas sensing property. The $40^{\circ} \mathrm{C}$ precipitated sample had similar diameter as those calcined at $60^{\circ} \mathrm{C}$, as well as a similar gas sensing performance. However, if the temperature increased to $80^{\circ} \mathrm{C}$, limited precipitate and product were obtained due to the relatively higher solubility of the $\operatorname{In}(\mathrm{OH})_{3}$ at higher temperatures. Though the particle size is a bit smaller $(\sim 30 \mathrm{~nm})$, the gas response only increased from 2.6 to 3.5 to $50 \mathrm{ppm}$ ethanol, showing the limited tailoring effect of the gas performance by particle size. On the other side, the response of $5 \mathrm{~mol} \%$ Ag-modified $\operatorname{In}_{2} \mathrm{O}_{3}$ exhibited a maximum significantly higher than any other samples at $300{ }^{\circ} \mathrm{C}$. The response is 67 to $50 \mathrm{ppm}$ ethanol, which is one of the highest in the literature, as shown in the comparison in Table 1, demonstrating the significant response improvement of $\operatorname{In}_{2} \mathrm{O}_{3}$ by Ag surface modification. In the meantime, the resistance of the gas sensor is in the level of $10 \mathrm{k} \Omega$, which would be favorable for easily integration with interfacing electronic circuits.

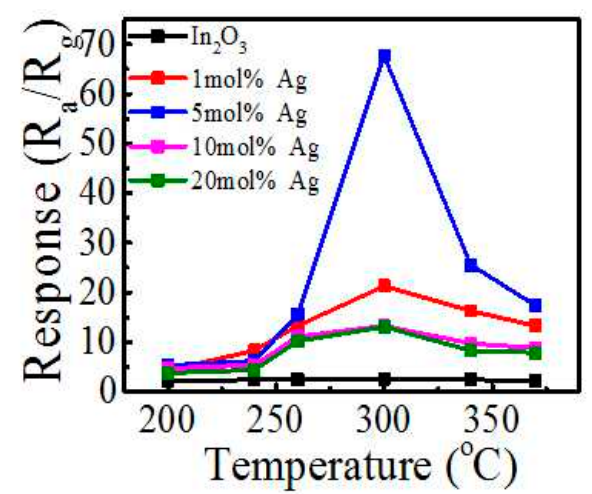

Figure 5. Responses vs operating temperatures of Ag-modified $\operatorname{In}_{2} \mathrm{O}_{3}$ nanomaterials.

Table 1. Sensing properties to ethanol and acetone of the different materials in our present study and in literature studies.

\begin{tabular}{cccccc}
\hline Material & Ethanol & Response & $\mathbf{T}\left({ }^{\circ} \mathbf{C}\right)$ & Resistance & Reference \\
\hline $\mathrm{Ag}$ doped $\mathrm{In}_{2} \mathrm{O}_{3}$ & $50 \mathrm{ppm}$ & 67 & 300 & $10 \mathrm{k} \Omega$ & This work \\
$\mathrm{In}_{2} \mathrm{O}_{3}$ microbundles & $50 \mathrm{ppm}$ & 11.6 & 300 & $10 \mathrm{k} \Omega$ & {$[15]$} \\
Flower-like $\mathrm{In}_{2} \mathrm{O}_{3}$ & $100 \mathrm{ppm}$ & 27.6 & 320 & $180 \mathrm{k} \Omega$ & {$[12]$} \\
$\mathrm{Au}$-loaded $\mathrm{In}_{2} \mathrm{O}_{3}$ & $100 \mathrm{ppm}$ & 6.5 & 140 & $100 \mathrm{k} \Omega$ & {$[28]$} \\
$\mathrm{Tb}$ doped $\mathrm{In}_{2} \mathrm{O}_{3}$ & $50 \mathrm{ppm}$ & 40 & 300 & $10 \mathrm{M} \Omega$ & {$[18]$} \\
$\mathrm{Rh}$-loaded $\mathrm{In}_{2} \mathrm{O}_{3}$ & $100 \mathrm{ppm}$ & 4748 & 371 & $50 \mathrm{M} \Omega$ & {$[29]$} \\
$\mathrm{TiO}_{2}$ nanoparticle & $20 \mathrm{ppm}$ & 6 & 400 & $1 \mathrm{G} \Omega$ & {$[30]$} \\
$\mathrm{SnO}_{2}$ nanoparticle & $1000 \mathrm{ppm}$ & 760 & 350 & $10 \mathrm{M} \Omega$ & {$[31]$} \\
\hline
\end{tabular}

To further explore the sensing property, response curve, and selectivity, responses to other interfering gases are measured in Figure 6. Figure 6a presents the response and recovery behaviors of the $5 \mathrm{~mol} \%$ Ag-modified $\operatorname{In}_{2} \mathrm{O}_{3}$ sensor. The response time can be defined as the time needed to reach $90 \%$ of its saturated pulse height, while the recovery time is the time needed for the pulse to reach $10 \%$ from its base line. We found that the response-recovery times are $22.3 \mathrm{~s}$ and $11.7 \mathrm{~s}$, respectively. In the meanwhile, the selectivity of the $5 \mathrm{~mol} \% \mathrm{Ag}$-modified $\mathrm{In}_{2} \mathrm{O}_{3}$ sensor is evaluated by exploring the response of $50 \mathrm{ppm}$ interfering gases included acetone, benzene, and $\mathrm{HCHO}$ at $300{ }^{\circ} \mathrm{C}$ (Figure $6 \mathrm{~b}$ ). It is observed that the Ag-modified $\operatorname{In}_{2} \mathrm{O}_{3}$ has a far higher response to ethanol than those to $\mathrm{HCHO}$ and benzene at the same concentrations, and even has a more than three times higher response to acetone. Those gases are typical pollutants detected in a car at the ppb to sub-ppm levels, which are released by the decorations and thus are the major interfering gases for ethanol detection. As ethanol from drinkers are tens of ppm in concentration, which is larger than those interfering gases, and the 
response to ethanol is also larger, the $5 \mathrm{~mol} \%$ Ag-modified $\operatorname{In}_{2} \mathrm{O}_{3}$ sensor thus has high selectivity for ethanol detection.
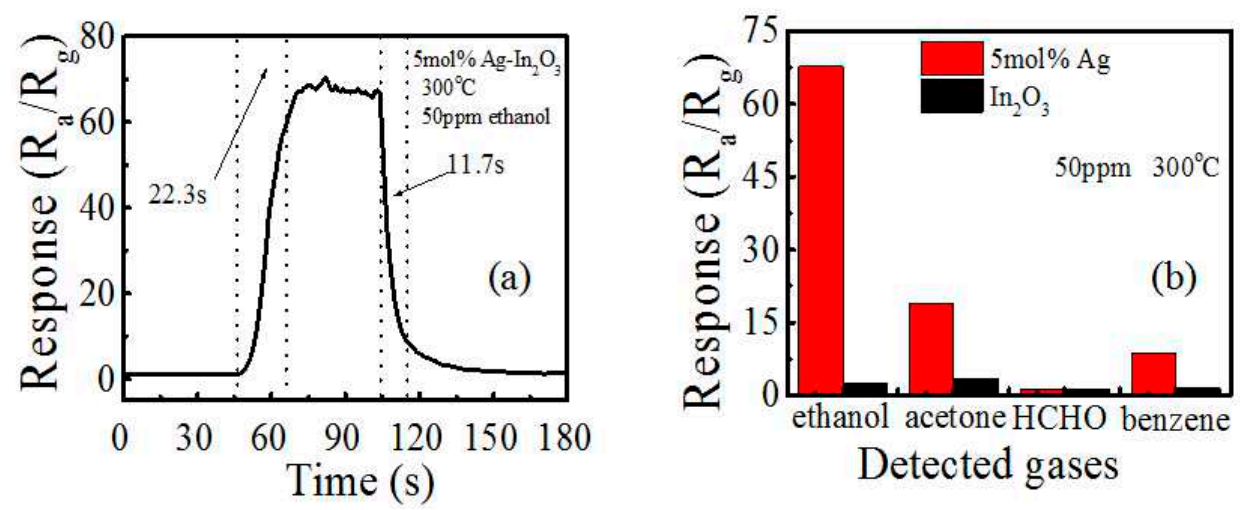

Figure 6. (a) The response-recovery characteristics of the $5 \mathrm{~mol} \%$ Ag-modified $\mathrm{In}_{2} \mathrm{O}_{3}$ sensor to $50 \mathrm{ppm}$ ethanol at $300{ }^{\circ} \mathrm{C} ;(\mathbf{b})$ the response of the $5 \mathrm{~mol} \% \mathrm{Ag}$-modified $\mathrm{In}_{2} \mathrm{O}_{3}$ sensor to $50 \mathrm{ppm}$ of different gas concentrations at $300^{\circ} \mathrm{C}$.

Figure 7a compares the response of pure and $5 \mathrm{~mol} \%$ Ag-modified $\operatorname{In}_{2} \mathrm{O}_{3}$ under lower ethanol concentrations (1-20 ppm). It is clear that the response values tend to have an approximately linear relationship with the concentration. More importantly, the response of $\mathrm{Ag}$-modified $\operatorname{In}_{2} \mathrm{O}_{3}$ is far higher at all concentrations. Generally, the detection limit is set at the concentration with the response of 2. It can be derived from Figure 7a that the detection of pure $\mathrm{In}_{2} \mathrm{O}_{3}$ is $>20 \mathrm{ppm}$ (response 1.7), while that of $5 \mathrm{~mol} \%$ Ag-modified $\mathrm{In}_{2} \mathrm{O}_{3}$ is about 1.5-2 ppm. To shed light on the origin of the enhanced response, the catalytic properties of pure and $5 \mathrm{~mol} \%$ Ag-modified $\mathrm{In}_{2} \mathrm{O}_{3}$ are compared, as shown in Figure $7 \mathrm{~b}$. It is noticed that the conversion increases with the rising reaction temperature, and has a striking improvement with Ag modification. The enhanced catalytic activity would be the main reason why Ag modification improved the gas sensing property.
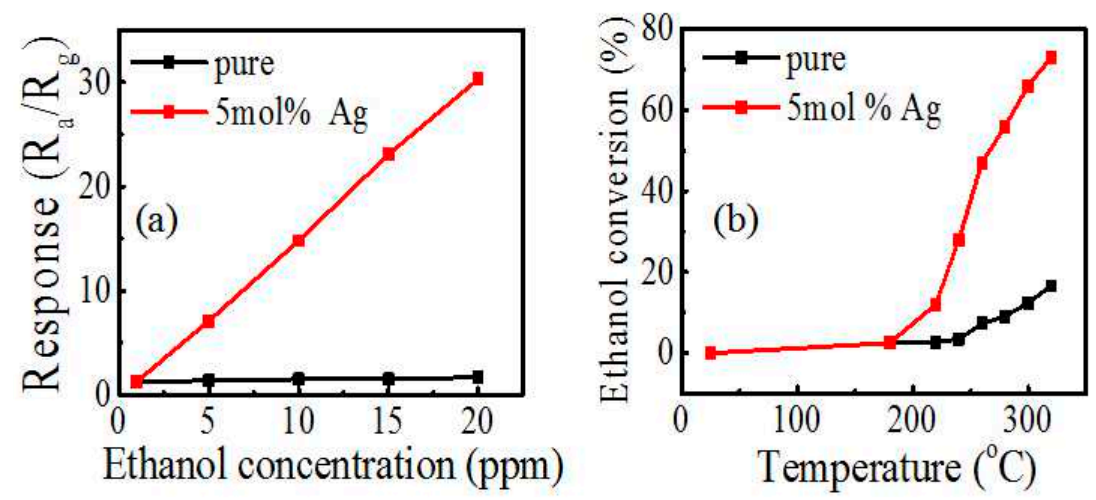

Figure 7. (a) Response change of the pure and $5 \mathrm{~mol} \%$ Ag-modified $\operatorname{In}_{2} \mathrm{O}_{3}$ sensors to different ethanol concentrations at $300{ }^{\circ} \mathrm{C}$; (b) ethanol conversion of the pure and $5 \mathrm{~mol} \% \mathrm{Ag}$-modified $\mathrm{In}_{2} \mathrm{O}_{3}$ sensors as a function of reaction temperature over catalysts.

\section{Discussion}

On the basis of the above experimental results, the gas sensing mechanisms of pure and $\mathrm{Ag}-\operatorname{In}{ }_{2} \mathrm{O}_{3}$ sensors are schematically shown in Figure 8. The dramatic enhancement in the ethanol gas sensing performance of $\mathrm{In}_{2} \mathrm{O}_{3}$-based nanomaterials via modification with $\mathrm{Ag}$ nanoparticles can be interpreted using the electron depletion layer model [32,33]. Currently, the adsorbed oxygen ions occupy the surface area of $\mathrm{In}_{2} \mathrm{O}_{3}$-based nanomaterials, forming the electron depletion layer (Figure 8a). 
The depleted electrons and the raised electron potential (Figure $8 \mathrm{~b}$ ) by the depletion layer contribute to the high resistance of the $\operatorname{In}_{2} \mathrm{O}_{3}$ sensor in air. When the sensor is exposed to ethanol, the reaction between oxygen and ethanol occurs, as shown in Equation (1) [34]. Then, the trapped electrons are released to the conduction band, contributing to the thinner depletion layer and the lower resistance of $\mathrm{In}_{2} \mathrm{O}_{3}$ sensors.

$$
\mathrm{C}_{2} \mathrm{H}_{5} \mathrm{OH}(\text { ads })+6 \mathrm{O}^{-}(\text {ads }) \rightarrow 2 \mathrm{CO}_{2(\mathrm{~g})}+3 \mathrm{H}_{2} \mathrm{O}+6 \mathrm{e}^{-}
$$

(a)

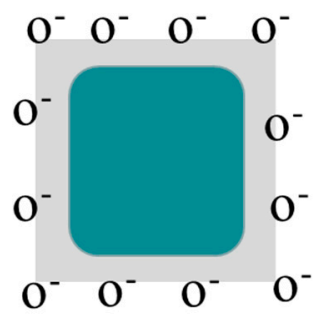

(c)

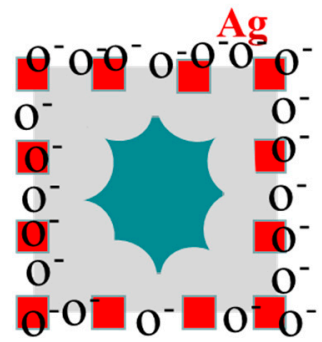

spillover effect (b)

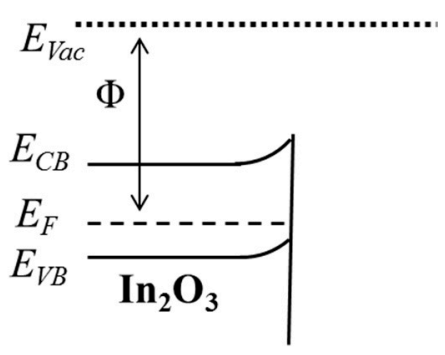

(d)

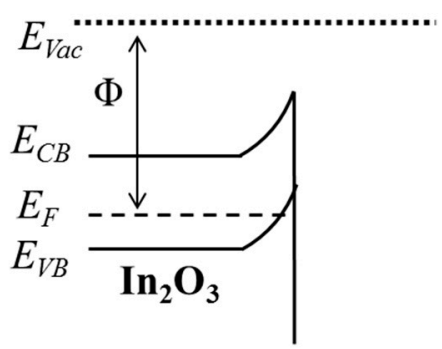

Figure 8. The schematic diagram (a) and energy band diagram $(\mathbf{b})$ of pure $\operatorname{In}_{2} \mathrm{O}_{3}$; the schematic diagram (c) and energy band diagram (d) of $5 \mathrm{~mol} \% \mathrm{Ag}$-modified $\mathrm{In}_{2} \mathrm{O}_{3}$. $\mathrm{E}_{\mathrm{CB}}$ and $\mathrm{E}_{\mathrm{VB}}$ are the conduction band and valence band level, $\mathrm{E}_{\mathrm{vac}}$ and $\mathrm{E}_{\mathrm{F}}$ represent the vacuum level and Fermi level.

On the other side, when Ag is deposited on the surface of $\operatorname{In}_{2} \mathrm{O}_{3}$, there would be more oxygen adsorbed on the surface due to the well-known spillover effect $[18,23,25]$, as shown in Figure $8 \mathrm{c}$. This way, Ag modification enhances the reaction between ethanol molecules and adsorbed oxygen ions on the surface of $\operatorname{In}_{2} \mathrm{O}_{3}$, leading to a higher response to ethanol. Meanwhile, the more ion-adsorbed oxygen will change the energy-band structure and give rise to the potential barrier as demonstrated in Figure $8 \mathrm{~d}$. Therefore, the enhanced reaction with ethanol and the higher electron potential barrier will contributed to the enhance ethanol response of the Ag-modified $\operatorname{In}_{2} \mathrm{O}_{3}$ materials. This agrees well with the literature, confirming that $\mathrm{Ag}$ is a good catalyst for ethanol because Ag can effectively enhance the ethanol conversion, and suppress ethanol dehydration as well $[35,36]$. All these results show the potential of the Ag-modified $\operatorname{In}_{2} \mathrm{O}_{3}$ materials for applications in ethanol sensing.

\section{Conclusions}

In summary, $\mathrm{In}_{2} \mathrm{O}_{3}$ nanomaterial is successfully prepared by a facile precipitation method and is further modified by Ag as verified by EDS, HRTEM, and UV-Vis absorption characterizations. A gas sensing property test showed that the $5 \mathrm{~mol} \% \mathrm{Ag}$-modified $\operatorname{In}_{2} \mathrm{O}_{3}$ nanomaterial has a high response of 67 to $50 \mathrm{ppm}$ ethanol, a fast response and recovery time of $10-20 \mathrm{~s}$, and a high selectivity over other interfering gases such as acetone, benzene, and formaldehyde. The enhanced gas sensing property is probably attributed to the higher catalytic activity to ethanol by the Ag modification as verified by the ethanol catalytic measurement. Lastly, the related mechanism is discussed in light of the spillover effect of $\mathrm{Ag}$ on the $\mathrm{In}_{2} \mathrm{O}_{3}$ surface. 
Acknowledgments: This research was financially supported by the National Key R\&D Program of China (2016YFC0207100), the National Natural Science Foundation of China (11575228), and the State Key Laboratory of Multiphase Complex Systems (MPCS-2014-C-01).

Author Contributions: Jinxiao Wang fabricated $\mathrm{Ag} / \mathrm{In}_{2} \mathrm{O}_{3}$ composite materials and measured the gas sensing and catalytic performances with Yuan Si and Xinyi Liu; Zheng Xie synthesized $\operatorname{In}_{2} \mathrm{O}_{3}$ nanoparticles; Xinyuan Zhou carried out the SEM and EDS characterization; Jianfeng Yang measured the XRD and TEM; Peng Hu carried out the Raman and absorption spectroscopies; Ning Han, Jun yang and Yunfa Chen designed the experiments and revised the manuscript.

Conflicts of Interest: The authors declare no conflict of interest.

\section{References}

1. Kolmakov, A.; Klenov, D.O.; Lilach, Y.; Stemmer, S.; Moskovits, M. Enhanced gas sensing by individual $\mathrm{SnO}_{2}$ nanowires and nanobelts functionalized with Pd catalyst particles. Nano Lett. 2005, 5, 667-673. [CrossRef] [PubMed]

2. Han, N.; Wu, X.F.; Zhang, D.W.; Shen, G.L.; Liu, H.D.; Chen, Y.F. CdO activated Sn-doped ZnO for highly sensitive, selective and stable formaldehyde sensor. Sens. Actuators B 2011, 152, 324-329. [CrossRef]

3. Han, N.; Chai, L.Y.; Wang, Q.; Tian, Y.J.; Deng, P.Y.; Chen, Y.F. Evaluating the doping effect of Fe, Ti and Sn on gas sensing property of ZnO. Sens. Actuators B 2010, 147, 525-530. [CrossRef]

4. Park, H.J.; Choi, N.J.; Kang, H.; Jung, M.Y.; Park, J.W.; Park, K.H.; Lee, D.S. A ppb-level formaldehyde gas sensor based on $\mathrm{CuO}$ nanocubes prepared using a polyol process. Sens. Actuators B 2014, 203, 282-288. [CrossRef]

5. Xu, K.; Zeng, D.W.; Wu, J.J.; Mao, Q.Q.; Tian, S.Q.; Zhang, S.P.; Xie, C.S. Correlation between microstructure and gas sensing properties of hierarchical porous tin oxide topologically synthesized on coplanar sensors' surface. Sens. Actuators B 2014, 205, 416-425. [CrossRef]

6. Zhang, Y.; Xu, J.Q.; Xiang, Q.; Li, H.; Pan, Q.Y.; Xu, P.C. Brush-like hierarchical ZnO nanostructures: Synthesis, photoluminescence and gas sensor properties. J. Phys. Chem. C 2009, 113, 3430-3435. [CrossRef]

7. Yang, C.; Xiao, F.; Wang, J.D.; Su, X.T. 3D flower- and 2D sheet-like CuO nanostructures: Microwave-assisted synthesis and application in gas sensors. Sens. Actuators B 2015, 207, 177-185. [CrossRef]

8. Chen, C.L.; Chen, D.R.; Jiao, X.L.; Chen, S.H. $\operatorname{In}_{2} \mathrm{O}_{3}$ nanocrystals with a tunable size in the range of 4-10 nm: One-step synthesis, characterization, and optical properties. J. Phys. Chem. C 2007, 111, 18039-18043. [CrossRef]

9. Inyawilert, K.; Wisitsora-at, A.; Tuantranont, A.; Singjai, P.; Phanichphant, S.; Liewhiran, C. Ultra-rapid vocs sensors based on sparked-In ${ }_{2} \mathrm{O}_{3}$ sensing films. Sens. Actuators B 2014, 192, 745-754. [CrossRef]

10. Yu, D.B.; Yu, S.H.; Zhang, S.Y.; Zuo, J.; Wang, D.B.; Qian, Y.T. Metastable hexagonal $\operatorname{In}_{2} \mathrm{O}_{3}$ nanofibers templated from InOOH nanofibers under ambient pressure. Adv. Funct. Mater. 2003, 13, 497-501. [CrossRef]

11. Xu, L.; Dong, B.A.; Wang, Y.; Bai, X.; Liu, Q.; Song, H.W. Electrospinning preparation and room temperature gas sensing properties of porous $\operatorname{In}_{2} \mathrm{O}_{3}$ nanotubes and nanowires. Sens. Actuators B 2010, 147, 531-538. [CrossRef]

12. Han, D.; Song, P.; Zhang, H.H.; Yan, H.H.; Xu, Q.; Yang, Z.X.; Wang, Q. Flower-like $\operatorname{In}_{2} \mathrm{O}_{3}$ hierarchical nanostructures: Synthesis, characterization, and gas sensing properties. RSC Adv. 2014, 4, 50241-50248. [CrossRef]

13. Kim, J.; Kim, W.; Yong, K. Cuo/zno heterostructured nanorods: Photochemical synthesis and the mechanism of $\mathrm{H}_{2} \mathrm{~S}$ gas sensing. J. Phys. Chem. C 2012, 116, 15682-15691. [CrossRef]

14. Lee, A.P.; Reedy, B.J. Temperature modulation in semiconductor gas sensing. Sens. Actuators B 1999, 60, 35-42. [CrossRef]

15. Li, Z.P.; Yan, H.; Yuan, S.L.; Fan, Y.J.; Zhan, J.H. $\mathrm{In}_{2} \mathrm{O}_{3}$ microbundles constructed with well-aligned single-crystalline nanorods: F127-directed self-assembly and enhanced gas sensing performance. J. Colloid Interface Sci. 2011, 354, 89-93. [CrossRef] [PubMed]

16. Wagh, M.S.; Jain, G.H.; Patil, D.R.; Patil, S.A.; Patil, L.A. Modified zinc oxide thick film resistors as $\mathrm{NH}_{3}$ gas sensor. Sens. Actuators B 2006, 115, 128-133. [CrossRef]

17. An, S.; Park, S.; Ko, H.; Jin, C.; Lee, W.I.; Lee, C. Enhanced ethanol sensing properties of multiple networked au-doped $\operatorname{In}_{2} \mathrm{O}_{3}$ nanotube sensors. J. Phys. Chem. Solids 2013, 74, 979-984. [CrossRef] 
18. Anand, K.; Kaur, J.; Singh, R.C.; Thangaraj, R. Effect of terbium doping on structural, optical and gas sensing properties of $\mathrm{In}_{2} \mathrm{O}_{3}$ nanoparticles. Mater. Sci. Semicond. Process. 2015, 39, 476-483. [CrossRef]

19. Montazeri, A.; Jamali-Sheini, F. Enhanced ethanol gas-sensing performance of $\mathrm{Pb}$-doped $\mathrm{In}_{2} \mathrm{O}_{3}$ nanostructures prepared by sonochemical method. Sens. Actuators B 2017, 242, 778-791. [CrossRef]

20. Fan, H.T.; Zeng, Y.; Yang, H.B.; Meng, X.J.; Liu, L.; Mang, T. Preparation and gas sensitive properties of ZnO-CuO nanocomposites. Acta Phys. Chim. Sin. 2008, 24, 1292-1296.

21. Peng, C.; Guo, J.J.; Yang, W.K.; Shi, C.K.; Liu, M.R.; Zheng, Y.X.; Xu, J.; Chen, P.Q.; Huang, T.T.; Yang, Y.Q. Synthesis of three-dimensional flower-like hierarchical $\mathrm{ZnO}$ nanostructure and its enhanced acetone gas sensing properties. J. Alloy Compd. 2016, 654, 371-378. [CrossRef]

22. Zeng, Y.; Qiao, L.; Bing, Y.F.; Wen, M.; Zou, B.; Zheng, W.T.; Zhang, T.; Zou, G.T. Development of microstructure $\mathrm{CO}$ sensor based on hierarchically porous $\mathrm{ZnO}$ nanosheet thin films. Sens. Actuators $B$ 2012, 173, 897-902. [CrossRef]

23. Liu, T.; Bai, X.; Miao, C.; Dai, Q.L.; Xu, W.; Yu, Y.H.; Chen, Q.D.; Song, H.W. $\mathrm{Yb}_{2} \mathrm{O}_{3} / \mathrm{Au}$ upconversion nanocomposites with broad-band excitation for solar cells. J. Phys. Chem. C 2014, 118, 3258-3265. [CrossRef]

24. Wang, S.M.; Xiao, B.X.; Yang, T.Y.; Wang, P.; Xiao, C.H.; Li, Z.F.; Zhao, R.; Zhang, M.Z. Enhanced HCHO gas sensing properties by Ag-loaded sunflower-like $\mathrm{In}_{2} \mathrm{O}_{3}$ hierarchical nanostructures. J. Mater. Chem. A 2014, 2, 6598-6604. [CrossRef]

25. Duan, Y.Y.; Zhang, M.; Wang, L.; Wang, F.; Yang, L.P.; Li, X.Y.; Wang, C.Y. Plasmonic Ag-TiO $2-x$ nanocomposites for the photocatalytic removal of NO under visible light with high selectivity: The role of oxygen vacancies. Appl. Catal. B Environ. 2017, 204, 67-77. [CrossRef]

26. Yang, H.X.; Wang, S.P.; Yang, Y.Z. Zn-doped $\mathrm{In}_{2} \mathrm{O}_{3}$ nanostructures: Preparation, structure and gas-sensing properties. Crystengcomm 2012, 14, 1135-1142. [CrossRef]

27. Linic, S.; Christopher, P.; Ingram, D.B. Plasmonic-metal nanostructures for efficient conversion of solar to chemical energy. Nat. Mater. 2011, 10, 911-921. [CrossRef] [PubMed]

28. Xu, X.J.; Fan, H.T.; Liu, Y.T.; Wang, L.J.; Zhang, T. Au-loaded $\operatorname{In}_{2} \mathrm{O}_{3}$ nanofibers-based ethanol micro gas sensor with low power consumption. Sens. Actuators B 2011, 160, 713-719. [CrossRef]

29. Kim, S.J.; Hwang, I.S.; Na, C.W.; Kim, I.D.; Kang, Y.C.; Lee, J.H. Ultrasensitive and selective $\mathrm{C}_{2} \mathrm{H}_{5} \mathrm{OH}$ sensors using Rh-loaded $\mathrm{In}_{2} \mathrm{O}_{3}$ hollow spheres. J. Mater. Chem. 2011, 21, 18560-18567. [CrossRef]

30. Rella, R.; Spadavecchia, J.; Manera, M.G.; Capone, S.; Taurino, A.; Martino, M.; Caricato, A.P.; Tunno, T. Acetone and ethanol solid-state gas sensors based on $\mathrm{TiO}_{2}$ nanoparticles thin film deposited by matrix assisted pulsed laser evaporation. Sens. Actuators B 2007, 127, 426-431. [CrossRef]

31. Punginsang, M.; Wisitsora-at, A.; Tuantranont, A.; Phanichphant, S.; Liewhiran, C. Effects of cobalt doping on nitric oxide, acetone and ethanol sensing performances of FSP-made $\mathrm{SnO}_{2}$ nanoparticles. Sens. Actuators $B$ 2015, 210, 589-601. [CrossRef]

32. Kohl, D. Surface processes in the detection of reducing gases with $\mathrm{SnO}_{2}$-based devices. Sens. Actuator 1989, 18, 71-113. [CrossRef]

33. Xu, C.N.; Tamaki, J.; Miura, N.; Yamazoe, N. Grain-size effects on gas sensitivity of porous $\mathrm{SnO}_{2}$-based elements. Sens. Actuators B 1991, 3, 147-155. [CrossRef]

34. Yu, L.M.; Liu, S.; Yang, B.; Wei, J.S.; Lei, M.; Fan, X.H. Sn-Ga co-doped ZnO nanobelts fabricated by thermal evaporation and application to ethanol gas sensors. Mater. Lett. 2015, 141, 79-82. [CrossRef]

35. Mamontov, G.V.; Magaev, O.V.; Knyazev, A.S.; Vodyankina, O.V. Influence of phosphate addition on activity of Ag and Cu catalysts for partial oxidation of alcohols. Catal. Today 2013, 203, 122-126. [CrossRef]

36. Marcu, I.C.; Tanchoux, N.; Fajula, F.; Tichit, D. Catalytic conversion of ethanol into butanol over M-Mg-Al mixed oxide catalysts $(\mathrm{M}=\mathrm{Pd}, \mathrm{Ag}, \mathrm{Mn}, \mathrm{Fe}, \mathrm{Cu}, \mathrm{Sm}, \mathrm{Yb})$ obtained from LDH precursors. Catal. Lett. 2013, 143, 23-30. [CrossRef]

(C) 2017 by the authors. Licensee MDPI, Basel, Switzerland. This article is an open access article distributed under the terms and conditions of the Creative Commons Attribution (CC BY) license (http:/ / creativecommons.org/licenses/by/4.0/). 